\title{
Los acuerdos de Esquipulas y los derechos del pueblo costeño
}

\author{
Francisco Campbell \\ Parlamento Centroamericano
}

En la década del ochenta del siglo pasado, cuando en Centroamérica los pueblos se desangraban en lo que se perfilaba como una guerra de alcance regional, sucedieron dos acontecimientos de gran repercusión en el destino de nuestros pueblos. En agosto de 1987, los cinco presidentes de Centroamérica suscribieron los históricos acuerdos de Esquipulas I y II y el 30 de octubre de ese mismo año, en nuestro país, se promulga el Estatuto de Autonomía de las Regiones Autónomas de la Costa Caribe Nicaragüense. Ambos sucesos tenían como objetivo fundamental propiciar la paz, procurando también que esa paz fuese firme y duradera mediante políticas y programas para eliminar la pobreza, el subdesarrollo, la inequidad y la marginación de amplios sectores.

Actualmente, todos los gobiernos de los países de la región, incluyendo los Gobiernos Regionales Autónomos, han sido electos democráticamente y es por ello que se puede afirmar, en lo que respecta a los aspectos de paz y democracia, que los réditos de Esquipulas I y II y de nuestra Autonomía han sido positivos, constituyéndose en un reflejo extraordinario de voluntad política asumida desde una perspectiva y visión regional.

Sin embargo, esa voluntad política de trabajar para la paz y profundización de la democracia formal no se hizo extensiva a otros aspectos contemplados en Esquipulas I y II, entre éstos el relanzamiento de la integración centroamericana mediante la creación y fortalecimiento de las instituciones comunitarias como el Parlamento Centroamericano y la Corte Centroamericana de Justicia. Pero, lo referido a nuestro Estatuto de Autonomía: la efectiva reintegración de los municipios de El Rama, Nueva Guinea, Muelle de los Bueyes y el Ayote a la Región Autónoma del Atlántico Sur y Mulukukú y Waslala a la RAAN, continúan siendo temas pendientes de nuestra agenda caribeña.

La lucha contra la pobreza, la desigualdad, la exclusión de pueblos indígenas y pueblos afrodescendientes, así como otros graves problemas sociales y económicos que fueron las verdaderas causas y trasfondo de los conflictos armados que por tantos años habían enlutado a los pueblos centroamericanos, tampoco fueron asumidos plenamente.

Desaprovechando el ambiente de paz propiciado por el proceso de Esquipulas, los gobiernos democráticamente electos se plegaron al Consenso de Washington: Impulsaron políticas neoliberales de ajuste estructural que han redundado en un mayor empobrecimiento del pueblo centroamericano; priorizaron la privatización de los servicios básicos; privilegiaron al sector financiero y comercial, desatendiendo la pequeña y mediana producción agropecuaria de importancia fundamental para el desarrollo sostenible que los mismos gobiernos centroamericanos consagraron como meta y objetivo regional al suscribir, en 1994, la Alianza para el Desarrollo Sostenible (ALIDES).

Luego de dos décadas de vigencia del proceso de Esquipulas y de nuestro proceso de Autonomía, las desigualdades entre nuestros pueblos son más grandes. A pesar de signos favorables de cambio en temas como el aumento de la esperanza de vida al nacer y la reducción en la mortalidad infantil, aún persisten grandes inequidades, desigualdades y desafíos con respecto a la pobreza, la discriminación, seguridad alimentaría, atención de las necesidades básicas, inseguridad ciudadana, el crimen organizado y el narcotráfico, la corrupción, vulnerabilidad ante desastres naturales, deterioro ambiental, entre otros graves problemas.

Asimismo, los altos índices de desempleo impulsan la migración y fuga de capital humano que la región necesita para lograr el desarrollo económico y social. Esta situación puede exacerbarse aún más con la actual crisis financiera mundial, afectando por un lado la demanda para nuestros principales productos de exportación en los mercados de Estados Unidos y Europa y por el otro, suscitando una fuerte reducción en las remesas hacia nuestros países que en el 2007 superaron los 16 mil millones de dólares. 


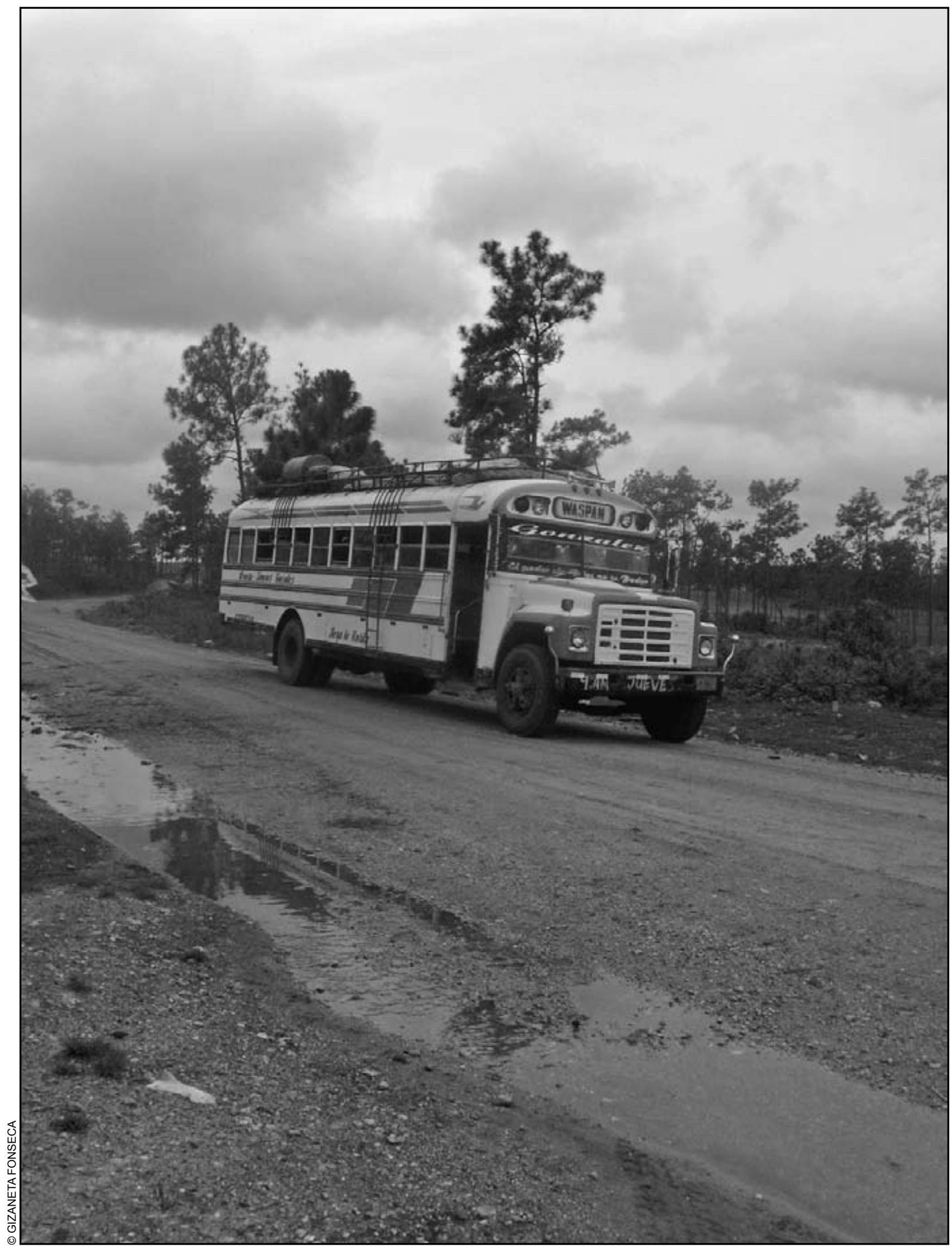

Carretera Waspam-Bilwi, 2008. 
Tales condiciones pueden minar y subvertir esa paz y democracia propiciada por Esquipulas I y II y el Estatuto de Autonomía de la Costa Caribe Nicaragüense y es por ello que el Parlamento Centroamericano, en coordinación con los Presidentes de las Comisiones de Asuntos Exteriores y de Integración de las Asambleas Legislativas de los países integrados al parlamento regional decidieron impulsar la convocatoria de Esquipulas III, considerando es urgente se retome el espíritu y la voluntad política demostrada por los Presidentes en 1987 para enderezar los esfuerzos y creatividades en la lucha frontal contra el subdesarrollo, principal flagelo de los pueblos centroamericanos.

La Alianza para el Desarrollo Sostenible de Centroamérica (ALIDES), el Nuevo Tratado de Integración Social; así como la estructura institucional del Sistema de Integración Centroamericana (SICA) y el ordenamiento jurídico de nuestro proceso de Autonomía, son instrumentos que recogen con toda claridad las diversas dimensiones del desarrollo que Esquipulas III retoma con mayor mérito. Constituye la continuidad histórica de Esquipulas I y II y por ser consistente con el anhelo de nuestros pueblos de restablecer la gran patria centroamericana, se le ha denominado "Esquipulas de los Pueblos"; como una propuesta a los gobiernos y a las fuerzas políticas y sociales de la región para continuar la obra iniciada con el proceso de Esquipulas en los años 80.

Reconoce la necesidad de hacer trabajar el ordenamiento comunitario centroamericano y de la Autonomía Regional mediante el fortalecimiento de las instituciones, el cumplimiento de sus objetivos y principios en el marco del desarrollo sostenible, igualdad, democracia y Estado de Derecho, explícitamente aceptando que el desarrollo integral de nuestros pueblos ha quedado como una asignatura pendiente, sin la cual no habrá una paz firme, justa y duradera.

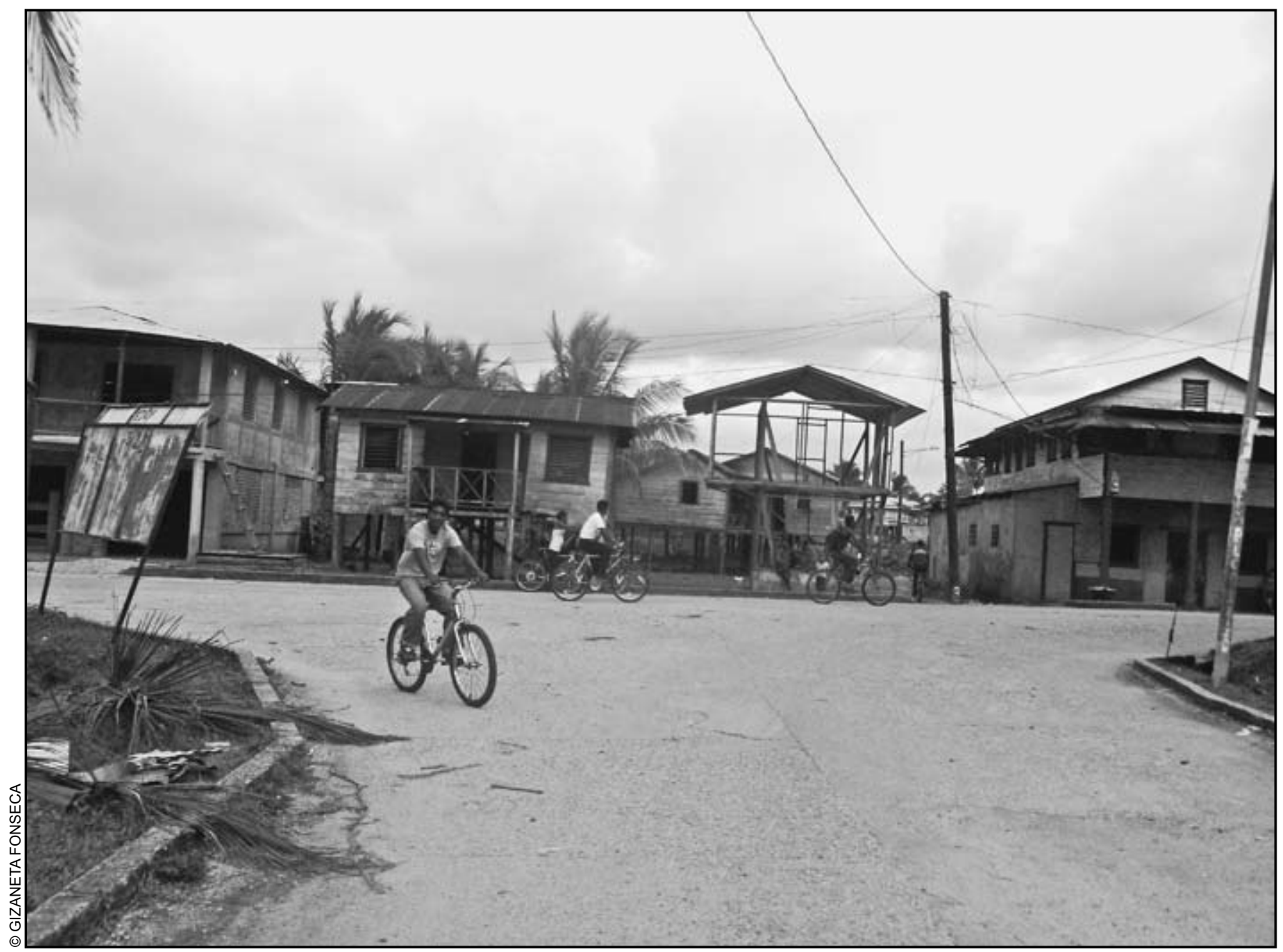

Luego de dos décadas de proceso de Autonomía las desigualdades entre nuestros pueblos persisten. Waspam 2008. 


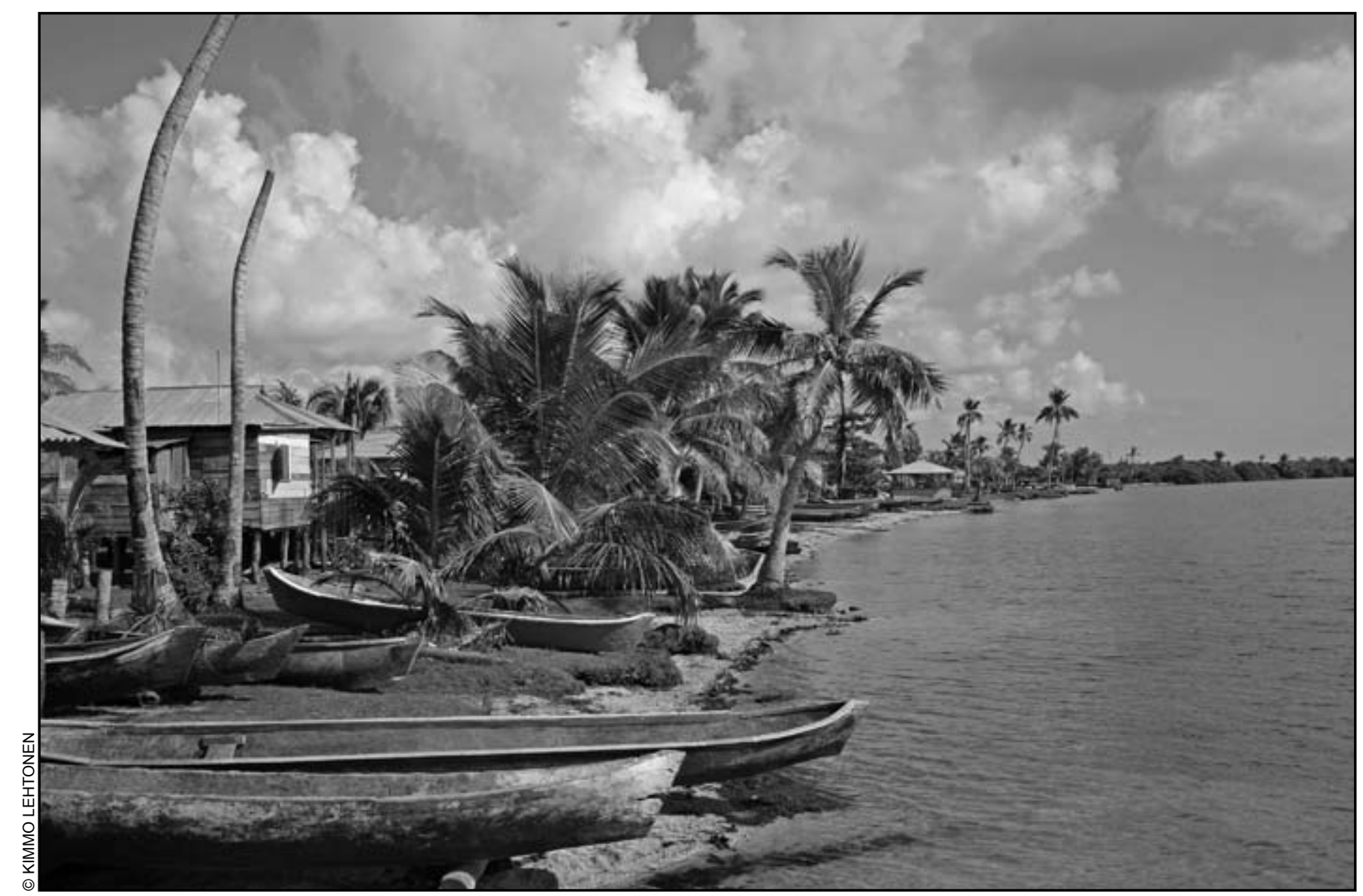

Playa de Krukira, abril 2009.

Esquipulas III contiene también un planteamiento interesante como es la creación del Parlamento Juvenil Centroamericano considerando el $64 \%$ de la población de la región es joven, constituyen el 49\% de la Población Económicamente Activa (PEA) y más del 50\% de la población en edad de votar. Este parlamento tendría la función de incidir en los procesos de formulación de políticas públicas de juventud, promovería el intercambio cultural entre las y los jóvenes de Centroamérica y el Caribe, así como con otras regiones del mundo, estimulando entre los jóvenes mayor conciencia de la integración centroamericana y otros aspectos de relevancia regional.

No se puede evadir ni postergar este desafío histórico de convocar a un nuevo acuerdo regional con participación de todas las fuerzas vivas de Centroamérica y República Dominicana, que permita la implementación de programas concretos y mecanismos de verificación para hacer de Centroamérica y República Dominicana una región desarrollada, cuyo crecimiento económico y social asegure la satisfacción de las necesidades fundamentales de nuestros ciudadanos y ciudadanas.

El cumplimiento de los compromisos adoptados por los Presidentes de la región en el marco del proceso de integración centroamericana y el apoyo de las Asambleas Legislativas, los partidos políticos, la sociedad civil, la comunidad internacional y sus organizaciones multilaterales, son condiciones básicas para alcanzar la cohesión social por la vía de la reforma estructural del sistema social y económico de la región, propiciando equidad en la distribución de oportunidades y acceso a los servicios y encausando a Centroamérica hacia el cumplimiento de los Objetivos de Desarrollo del Milenio, antes del 2015.

Un avance estratégico que viene a fortalecer la posibilidad de una mayor y más efectiva participación de la Regiones Autónomas en estas nuevas e interesantes oportunidades, ha sido el establecimiento de la Bluefields Indian and Caribean University (BICU) y la Universidad de las Regiones Autónomas de la Costa Caribe Nicaragüense 
(URACCAN). La plena integración de nuestra Costa Caribe es fundamental para el desarrollo de nuestro país y de Centroamérica y para ello, las universidades de nuestra Costa Caribe tienen que adecuar sus programas y planes de estudio para promover la formación de profesionales que puedan desenvolverse eficazmente dentro de una economía integrada nacional y regionalmente, e insertada dentro de un entorno globalizado.

En momentos cuando nuestro país asume su vocación caribeña, las Regiones Autónomas están llamadas a convertirse en eje importante dentro de esa estrategia de desarrollo nacional que contempla obras de infraestructura como las carreteras Managua-Bilwi, Nueva GuineaBluefields, el proyectado Puerto en Monkey Point y el aeropuerto internacional en Bilwi, municipio de Puerto Cabezas. Ello representaría mayor acceso y a menor costo para la exportación de los bienes que aquí se producen hacia los mercados del caribe, las costas del este y sur de Estados Unidos, la Unión Europea y países suramericanos como Venezuela, Colombia y Brasil, reduciendo a su vez los costos de los productos importados del pacífico y centro del país, así como del extranjero.

Nuestros recursos naturales y rica biodiversidad manejados desde una perspectiva de desarrollo sostenible y enfoque regional, pueden transformar a Nicaragua y Centroamérica en un importante actor en el escenario internacional, aprovechando mejor las enormes oportunidades que representa un mercado de 35 millones de habitantes, ubicado en una región de importancia estratégica para el tránsito internacional.

Una Centroamérica unida y cohesionada debe tener seguridad y confianza en sus capacidades para entrar en negociaciones en momentos en que se está propiciando la multi-polaridad económica-financiera, como resultado del reacomodo en los mercados y bolsas de valores europeas y asiáticas frente al debacle financiero en Estados Unidos y cuando instituciones como el Banco Mundial y el Fondo Monetario Internacional, creadas hace mas de cincuenta años para impulsar la reconstrucción después de la Segunda Guerra Mundial, están readecuando sus políticas y funcionamiento a las nuevas realidades del Siglo XXI.

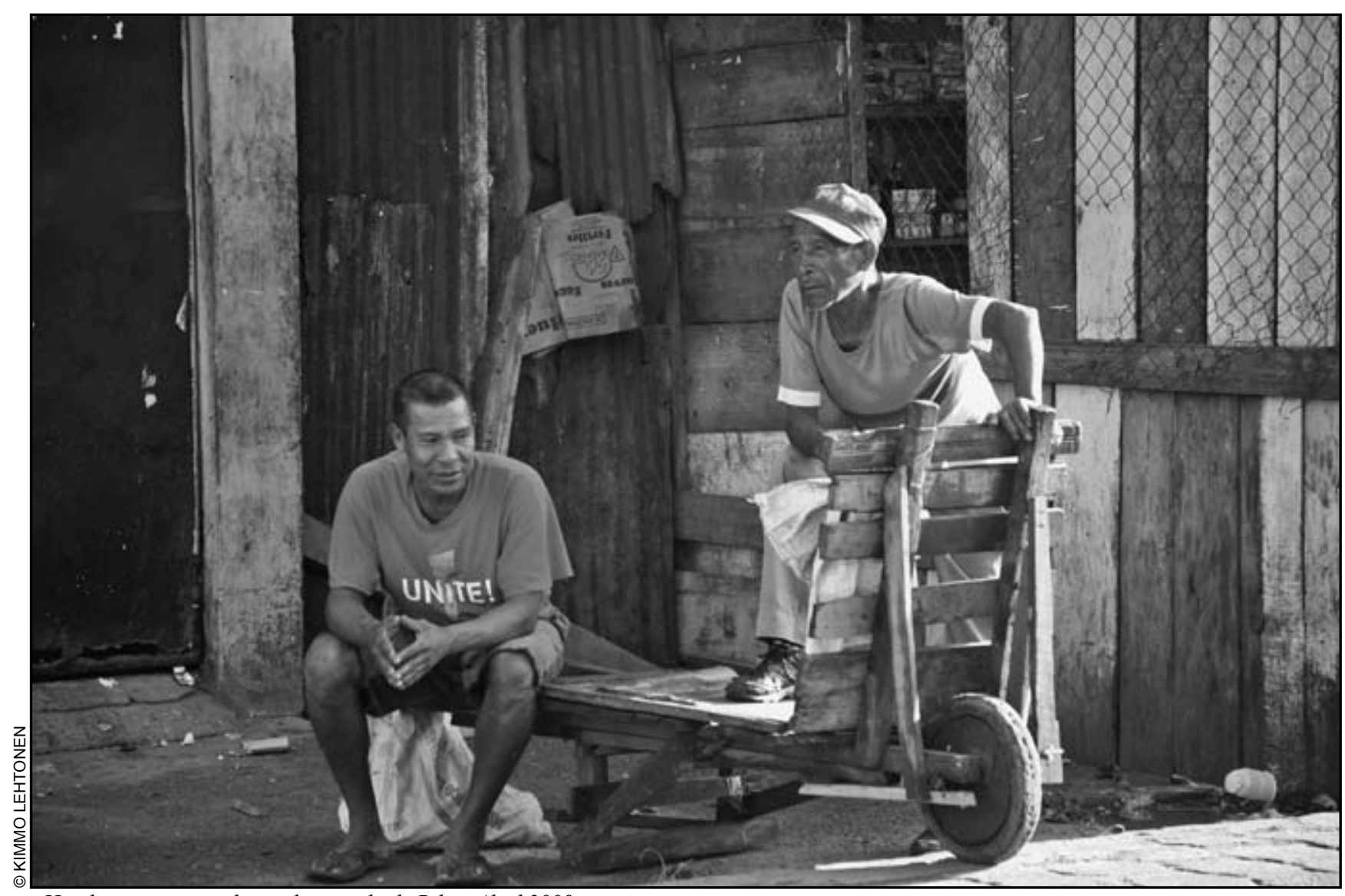

Hombres conversando en el mercado de Bilwi. Abril 2009. 


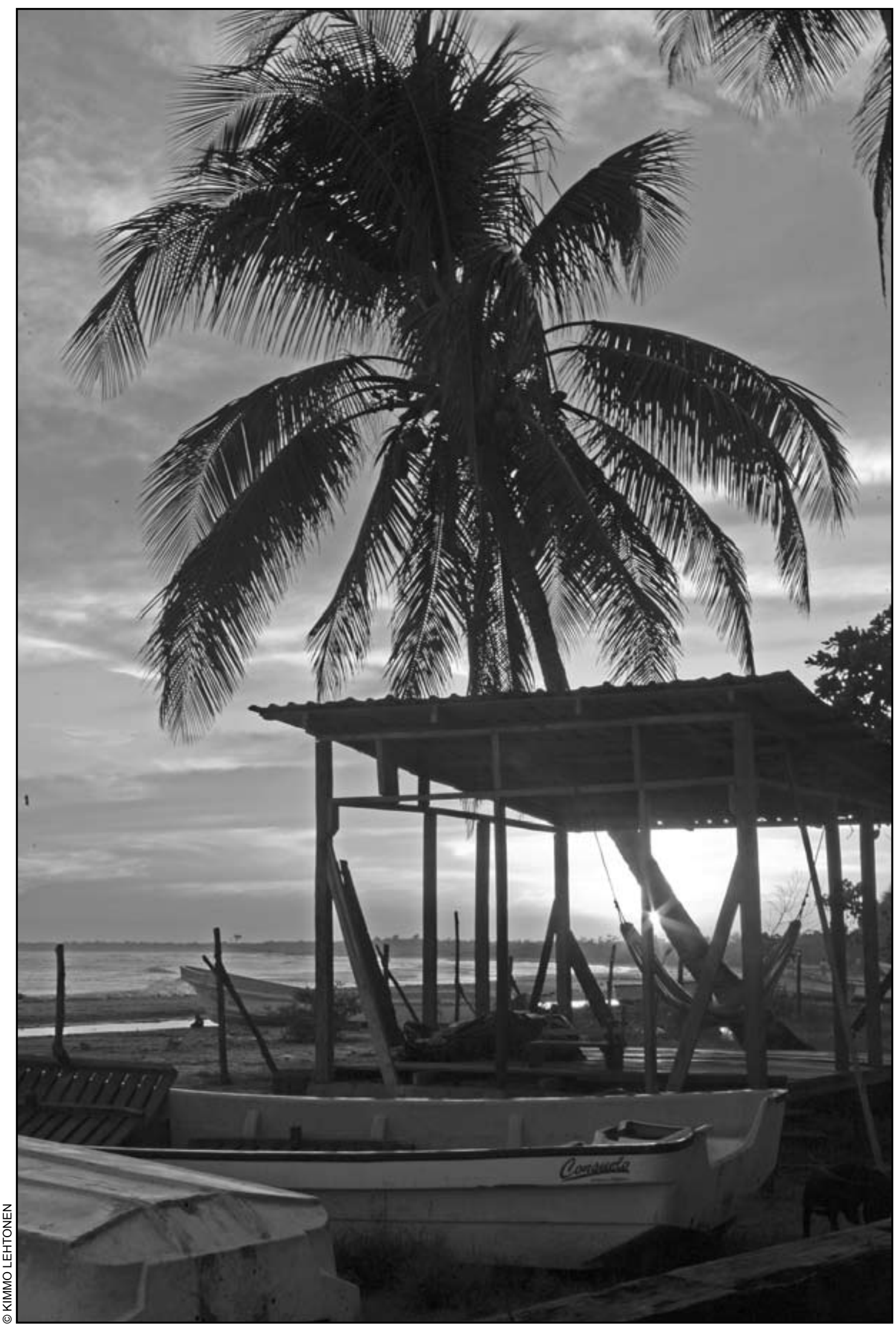

La plena integración de la Costa Caribe es fundamental para el desarrollo del país. Abril 2009. 
Los prejuicios ideológicos no deben constituirse en obstáculo para la negociación de acuerdos mutuamente beneficiosos con Petrocaribe o la Alternativa Bolivariana de las Américas (ALBA). Una Centroamérica fortalecida y clara en cuanto a sus objetivos de progreso y desarrollo en beneficio de nuestros pueblos, puede asumir estos retos y otros más, aprovechando las oportunidades que representa la creciente presencia de potencias comerciales emergentes como Brasil, la India y República Popular China.

Asimismo, se debe administrar con mejor tino el Acuerdo de Libre Comercio (DR-CAFTA) suscrito con Estados Unidos, procurando neutralizar los aspectos nocivos de esa desafortunada negociación, evitando cometer los mismos errores en las actuales negociaciones con la Unión Europea y defendiendo con firmeza el principio del Comercio Justo.

La toma de posesión el 20 de Enero del 2009 del primer Presidente afrodescendiente en la historia de Estados Unidos de Norteamérica, electo bajo el lema de “EL CAMBIO QUE SE NECESITA”, se perfila como un gran evento transformador. No se puede predecir con exactitud la naturaleza, el alcance, ni las dimensiones de los cambios que serán implementados por una administración liderada por el Presidente Barack Obama, pero su obvia disposición hacia el diálogo y la negociación en lugar del unilateralismo impositivo del gobierno de George W. Bush, permite especular sobre las perspectivas de un enfoque y tono mas pragmático en la formulación y conducción de la política exterior de ese importante país durante su mandato.

Estos grandes eventos seguramente tendrán repercusiones en todos los rincones del planeta y el país, o grupo de países, que mejor se preparen podrán aprovechar los beneficios que puedan derivarse de estas transformaciones y caso contrario, estarán en mejores condiciones para neutralizar cualquier aspecto negativo o desfavorable que pueda suscitarse.

Estos nuevos desafíos que hace unos meses ni se perfilaban sobre el horizonte, traen a colación la imperiosa necesidad de la realización de "Esquipulas III-Esquipulas de los Pueblos", para que los costeños y costeñas, nicaragüenses en general y todos los centroamericanos y caribeños podamos retomar con mayor firmeza y vigor este proceso estratégico mediante la profundización de la integración nacional y regional, propiciando el avance político, de seguridad y sobretodo el desarrollo social y económico: convirtiendo a nuestras naciones en una verdadera comunidad económico-política; con una agenda común mas incluyente y participativa; promoviendo la prosperidad y el reconocimiento de nuestras características multiétnicas y pluriculturales como base de la identidad nicaragüense y de la nación centroamericana.

\section{FE DE ERRATA}

